\title{
INFLUENCE OF SEVERE PLASTIC DEFORMATION PROCESS ON MECHANICAL PROPERTIES OF LOW CARBON STEEL
}

\author{
Stanislav RUSZ ${ }^{1}$, Ondřej HILŠER ${ }^{1}$, Pavel SZKANDERA ${ }^{1}$, Rostislav ZABYSTRZAN ${ }^{2}$, Jiří ŠVEC ${ }^{1}$, \\ Vratislav MARES ${ }^{1}$, Marcel KLOS ${ }^{3}$ \\ ${ }^{1}$ VSB - Technical University of Ostrava, Ostrava, Czech Republic, EU, stanislav.rusz@vsb.cz \\ ${ }^{2}$ STEELTEC CZ, s. r. o., Trinec, Czech Republic, EU, rostislav.zabystrzan@steeltec.cz \\ ${ }^{3}$ Tatra Trucks, a.s., Koprivnice, Czech Republic, EU, marcel.klos@tatra.cz
}

https://doi.org/10.37904/metal.2019.806

\begin{abstract}
Method DRECE (Dual Rolls Equal Channel Extrusion) belongs to a perspective group of technologies utilizing the process of severe plastic deformations (SPD). Used for forming of metallic materials. On the newly developed forming device, unlike the rolling technology, the material is significantly strengthening after the forming process, while maintaining the initial strip sheet dimensions. We want to achieve a significant increase in mechanical properties in as few passages as possible by the forming device, in particular increasing the yield strength $R_{e}$ and the ultimate tensile strength $R_{m}$, while maintaining good formability. The above-described forming method was used to extrude of low carbon steel. Overall, the effect of the individual passages on the increasing of mechanical properties of low carbon steel as tested in a total number of 1 to 7 passes through forming device. The forming tool, according to the pre-performed experiments, was chosen with an inclination of $108^{\circ}$ in the deformation zone. The mechanical properties obtained after each pass through the forming device from the tensile tests and the influence of the anisotropy of steel on the mechanical properties were analyzed and the microstructure of the strip sheet was evaluated.
\end{abstract}

Keywords: Severe plastic deformation process, DRECE method, forming device, anisotropy of strip sheet, mechanical properties, microstructure

\section{INNOVATIVE FORMING EQUIPMENT}

Device "DRECE - Dual Rolls Equal Channel Extrusion" (Dual Rolls Pressure Combined with Equal Channel Extrusion) is used for production of metallic materials with very fine grain size. During the actual forming process the principle of severe plastic deformation is used. The device is composed of the following main parts: "Nord" type gearbox, electric motor with frequency speed converter, multi-plate clutch, feed roller and pressure rollers with regulation of thrust, and of the forming tool itself - made of Dievar steel type. Metallic strip with dimensions $58 \times 2 \times(1000-2000) \mathrm{mm}$ (width $x$ thickness $x$ length) is inserted into the device. During the forming process the main cylinder in synergy with the pressure roller extrude the material through the forming tool without any change of cross section of the strip. In this way a significant refinement of grain is achieved by severe plastic deformation. This method is used for various types of metallic materials, non-ferrous metals and their alloys. Forming process is based on extrusion technology with zero reduction of thickness of the sheet metal with the ultimate aim - achieving a high degree of deformation in the formed material. Used DRECE process belongs to the group of a progressive type of forming processes making use of severe plastic deformation (SPD). After this processing step in comparison with structure of conventional materials, the materials exhibit significantly higher mechanical values, especially yield stress and in limited extent also tensile strength. The entire DRECE equipment is shown in Figure 1.

\section{INTRODUCTION}

Ultra-fine-grained materials (UFG materials) were developed in a number of research projects. Research has found that, that forming methods using severe plastic deformations process are very effective in the field of 
production of UFG materials. The SPD methods allow grain sizes of 100 to $200 \mathrm{~nm}$ to be achieved [1]. The resulting grain size can be affected by adjusting the forming parameters, for example by increasing the deformation pressure or by lowering the material temperature during forming [2,7]. The chemical composition of the formed material also has a significant effect on the resulting grain size [3]. The particle size of the grain mainly influences the degree of alloying of the formed material by interstitial atoms. Alloys formed by SPD methods achieve an increase in plasticity, strength or toughness. At UFG alloys also show effect superplasticity [6].
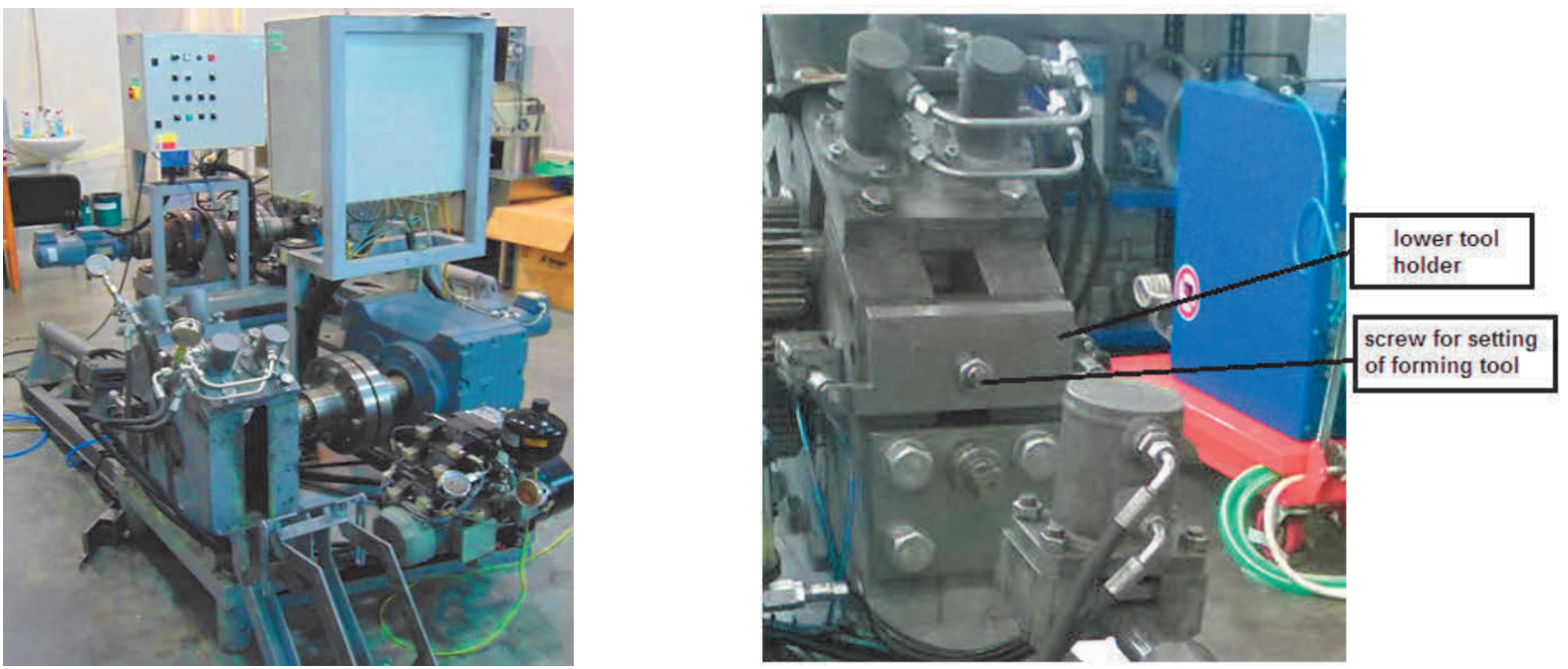

Figure 1 Forming equipment

One type of low carbon steels suitable for cold forming were verified experimentally- steel DC01. The tests were performed on the upgraded forming equipment using the principle of cold severe plastic deformation (method DRECE) [4,5]. Apart from materials, particularly the geometry of the forming tools is a very important factor of the forming method DRECE. The effect of degrees angle in the area of deformation on increasing the basic mechanical properties, especially yield strength $R_{p 0.2}$, ultimate tensile strength $R_{m}$, ductility $\mathrm{A}_{80}$, determined by tensile test, was tested also from this perspective.

\section{ANALYSIS OF SPD PROCESS INFLUENCE ON MECHANICAL PROPERTIES (CLASSIC TENSILE TESTS)}

Experimentally was carried out 7 passes through the forming device. After each pass, the mechanical properties obtained were evaluated. Chemical composition of tested steel is in Table 1.

Table 1 Chemical composition of tested steel (wt\%)

\begin{tabular}{|c|c|c|c|c|c|c|c|c|}
\hline $\mathbf{C}$ & $\mathbf{M n}$ & $\mathbf{S i}$ & $\mathbf{P}$ & $\mathbf{S}$ & $\mathbf{C r}$ & $\mathbf{N i}$ & $\mathbf{M o}$ & $\mathbf{C u}$ \\
\hline 0,050 & 0,203 & 0,020 & 0,014 & 0,008 & 0,053 & 0,056 & 0,005 & 0,075 \\
\hline
\end{tabular}

On the basis of the results obtained from the tensile tests, it can be stated with respect to the initial state, that after the $1^{\text {st }}$ passes the yield strength $R_{p 0,2}$ is increased by $51.7 \%$ and the ultimate tensile strength $R_{m}$ by 10 $\%$. At the same time, there will be a slight decrease in the ductility by $25 \%$. After the $5^{\text {th }}$ passes through the forming tool, the yield strength $R_{p 0,2}$ increased by $87 \%$ and the ultimate tensile strength $R_{m}$ increased by $42 \%$ relative to the initial state. As it is seen from these tables the yield strength and ultimate tensile strength after SPD processing are increased while the elongation $A_{80}$ is decreased. The ductility value $A_{80}=44 \%$ is sufficient after the five passes through forming tool (see Figures $\mathbf{2} \mathbf{a}, \mathbf{b}, \mathbf{c}$ ). 

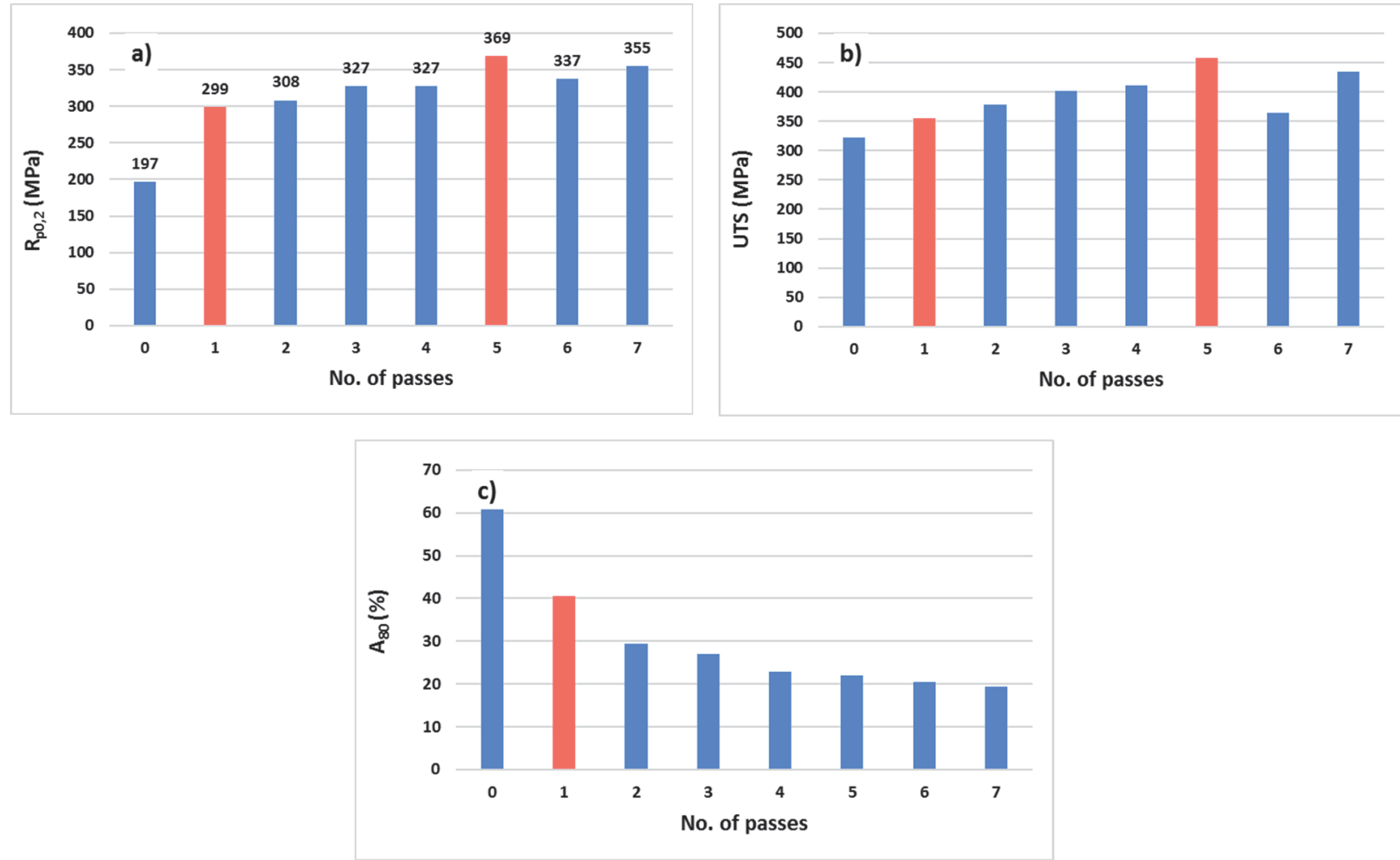

Figure 2 Influence of SPD process on: a) Yield Strength, b) Ultimate Tensile Stress, c) Ductility

\subsection{Microhardness of DC01 steel}

Achieved microhardness values are consistent with mechanical properties. The highest value is reached after the 5th passes through the forming tool (see Figure 3 and 4). The highest increase in hardness is achieved after the 1 st passes by the forming device. This is an important note for industrial applications.

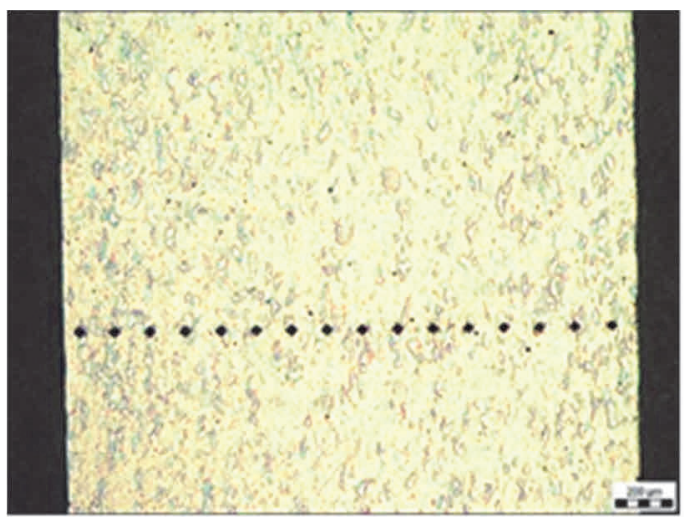

Figure 3 Measured injection site

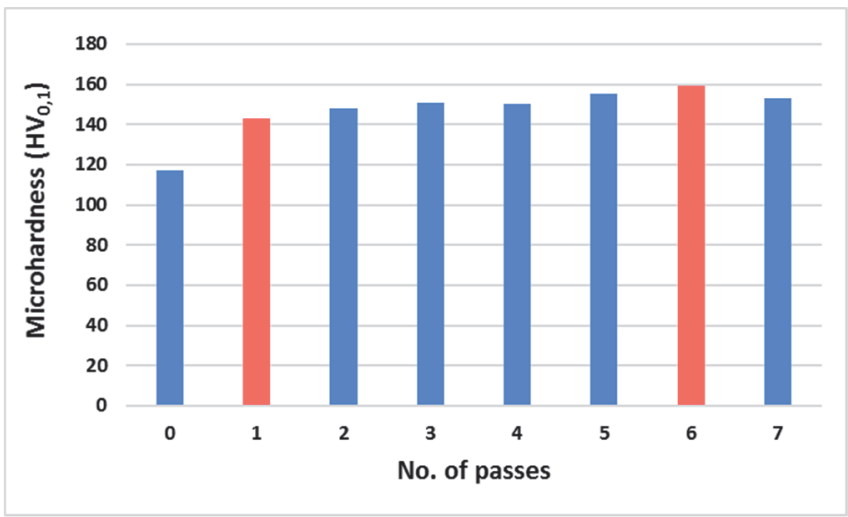

Figure 4 Influence of SPD process on microhardness in the transverse direction

\section{CONCLUSION}

From the results of the experiments, the effect of the SPD process on the quality improvement of the DC01 steel is obvious. In particular, it is an increase in the yield strength while maintaining the desired formability after the 1st passes by the forming device. Maximum values of mechanical properties and microhardness were 
reached after the 5th pass. At the same time, there is a considerable reduction in the formability (ductility). A dislocation-reinforced structure was achieved. In terms of grain refinement, which is important to maintain the required ductility, it will be desirable to carry out a suitable inter-operative heat treatment.

For the application of prototype equipment in industrial practice, the mechanical properties of the DC01 steel are very important. After the 1 st pass through the forming device, the yield strength $R p_{0,2}$ is substantially increased, while maintaining the necessary ductility $\left(A_{80}\right)$ required to further strain the sheet metal. The suitability of using the DRECE method to improve the quality of DC01 steel on prototype forming equipment has been clearly demonstrated.

\section{ACKNOWLEDGEMENTS}

This paper was created within the projects Ministry of Education, Youth and sports of Czech Republic for its support to the project Pre-seed Materials IA3, Production technology of a sheet strip with an ultra- fine grain structure, No. CZ.1.05/3.1.00/14.0320, project Epsilon Technology Agency of the Czech Republic, Development of a new technology for increasing the quality of steel strips, No.

TH04010416 and project Innovative and additive manufacturing technology - new technological solutions for $3 D$ printing of metals and composite materials, reg. no.

CZ.02.1.01/0.0/0.0/17_049/0008407 financed by Structural and Investment Founds of Europe Union.

\section{REFERENCES}

[1] TOTH, Laszlo S., GU, Chengfan, Ultrafine-grained metals by severe plastic deformation. Materials Characterization. 2014. vol. 92, pp. 1-14.

[2] VALIEV, Ruslan Z., ISLAMGALIEV, Rinat K. and ALEXANDROV Igor V. Bulk nanostructured materials from severe plastic deformation. Progress in Materials Science. 2000. vol. 42, pp. 103-189.

[3] ZRNÍK, Josef, DOBATKIN, Sergey V. and MAMUZIČ, Igor. Processing of metals by severe plastic deformation (SPD)-structure and mechanical properties respond. Metalurgija. 2008. vol. 47, pp. 211-216.

[4] HILŠER, O., SALAJKA, M. and RUSZ, S. Study of the mechanical properties of steel and selected types of nonferrous alloys after application of the DRECE process. In NANOCON 2015: 7th International Conference on Nanomaterials-Research \& Application. Ostrava: Tanger, 2015, pp. 163-167.

[5] RUSZ, S., KRAUS, M., HILŠER, O., ŠVEC, J., KEDROŇ, J., Čí̌̌EK, L., DONIČ, T., TAŃSKI, T. and KREJČí, L. Increasing the quality of DC01 steel by DRECE method. In METAL 2017: 26th International Conference on Metallurgy and Materials. Ostrava: Tanger, 2017, pp. 527-532.

[6] SNOPIŃSKI, Przemysław and TAŃSKI, Tomasz. Effect of heat treatment combined with high pressure torsion process on microstructure and hardness of AlMg5Si2Mn alloy. Solid State Phenomena. 2018. vol. 275, pp. 89-99.

[7] ČADA, R. Formability of deep-drawing steel sheets. In: Proceedings of the 5th European Conference on Advanced Materials and Processes and Applications (EUROMAT 97): Materials, Functionality Design: Volume 4 Characterization and Production/Design. Red. L. A. J. L. Sarton a H. B. Zeedijk. Netherlands, Maastricht: Netherlands Society for Materials Science, 1997, s. 463-466. ISBN 90-803513-4-2. Accession Number: WOS:A1997BJ43P00097. IDS Number: BJ43P. 